\title{
DISSONÂNCIAS E RESSONÂNCIAS DA FILOSOFIA KANTIANA SOBRE A FILOSOFIA DE MAINE DE BIRAN
}

\author{
André Renato de Oliveira ${ }^{1}$ \\ Universidade Federal de São Carlos (UFSCAR) \\ iD https://orcid.org/0000-0003-3840-0635 \\ E-mail: andrerpro@hotmail.com
}

\section{RESUMO:}

O objetivo deste artigo é questionar a legitimidade da intervenção determinante da filosofia de Kant sobre a filosofia de Maine de Biran. Sustentaremos, nesta pesquisa, que o biranismo não é uma espécie de kantismo e que as oposições do filósofo francês ao filósofo alemão são mais contundentes do que as aparentes compatibilidades entre elas. Para comprovar essa proposição, demonstraremos que as teses biranianas são essencialmente biranianas, contestando as palavras de Lachelier de que "Maine de Biran é o nosso Kant”, e, também, que Maine de Biran nunca foi um kantiano em stricto sensu, seguindo uma via oposta à do filósofo alemão, distanciando-se de sua filosofia e de qualquer influência determinante de Kant.

PALAVRAS-CHAVE: Maine de Biran; Kant; Kantismo; Biranismo.

\section{DISSONANCES AND RESONANCES OF KANTIAN PHILOSOPHY ON MAINE DE BIRAN}

\begin{abstract}
:
The purpose of this paper is to question the legitimacy of the intervention that determines Kant's philosophy over Maine's philosophy of Biran. We will maintain, in this research, that Biranism is not a kind of Kantism and that the French philosopher's oppositions to the German philosopher are more striking than the apparent compatibility between them. To prove this proposition, we will demonstrate that the Biranian theses are essentially Biranian, contesting the words of our Lachelier that "Maine de Biran is Kant", and also that Maine de Biran was never a Kantian in strict sense, following a path opposite to that of the German philosopher, distancing himself from his philosophy and from any determinant influence of Kant.
\end{abstract}

KEYWORDS: Maine de Biran; Kant; Kantianism; Biranism.

\footnotetext{
${ }^{1}$ Doutor(a) em Filosofia pela Universidade Estadual de Campinas (UNICAMP), Campinas -SP, Brasil. Pós-doutorando(a) em Filosofia na Universidade Federal de São Carlos (UFSCAR), São Carlos -SP, Brasil.
}

OLIVEIRA, André Renato de. Dissonâncias e ressonâncias da filosofia kantiana sobre a filosofia de Maine de Biran. Griot : Revista de Filosofia, Amargosa - BA, v.21 n.3, p.408-425, outubro, 2021. 


\section{Introdução}

Ao analisarmos os escritos de Maine de Biran nos deparamos com posicionamentos tomados pelo autor que são capazes de nos induzir a outorgar certa importância dada por ele ao sistema kantiano, tomando-o como peça fundamental ao desenvolvimento de sua filosofia; contrários a essa posição, sustentamos que o sistema kantiano não lhe interessaria mais do que aquele de Descartes ou de Leibniz, e vamos além, o sistema deste último parece agradar-lhe consideravelmente mais. Num primeiro momento, a constatação da relação de Biran com o sistema kantiano pode ser questionada pela conhecida correspondência entre Biran e Ampère, datada de setembro de 1812, na qual este último escreve a Maine de Biran: "Vós não tens nenhuma ideia de Kant, senão aquele presente na 'História dos sistemas de filosofia', de Degérando e do trabalho de Villers...". ${ }^{2}$ Realmente, as críticas vindas de Ampère são contundentes, pois Biran leu os trabalhos de Villers e de Degérando, mas seriam essas críticas totalmente verídicas? Às questões: Maine de Biran teria se limitado a essas leituras? Ou Maine de Biran realmente não conheceu nenhuma das obras de Kant?, de imediato respondemos que Maine de Biran leu alguns dos trabalhos de Kant, como a Dissertação de 1770, As formas e os princípios do mundo sensível e inteligível e Observações sobre o sentimento do belo e do sublime. É provável, ainda, que ele conhecesse outros trabalhos de Kant traduzidos. Refirimo-nos às dissertações latinas, o que não demonstraria uma total ignorância dos escritos de Kant. Tais afirmações podem ser verificadas sem muito esforço nos textos de Maine de Biran. Situado donde advém o conhecimento de Maine de Biran do sistema kantiano, cabe-nos expor o que consideramos os indícios daquilo que poderia ser considerado sua influência sobre a filosofia de Maine de Biran.

Isto posto, chama-nos a atenção uma anotação feita por Maine de Biran em seu "Jornal Íntimo", datado de 30 de maio de 1815. Nele, o filósofo francês escreve: "Tenho meditado durante quatro horas na parte da manhã com prazer e sucesso sobre as ideias de Kant, e o que tenho anotado entrará em meu trabalho [...]". E em 22 de junho do mesmo ano: "Tenho iniciado a leitura dos materiais psicológicos que reuni após dois meses de anotações sobre Kant, Lignac etc., a fim de realizar os prolegômenos de um trabalho fundamental sobre a ciência dos princípios [...]". Embora breves, essas passagens destacam questões importantes e, em certa medida, esclarecedoras; primeiramente, temos a constatação de que Maine de Biran realmente se deteve à análise de textos kantianos, não só indiretamente; outra questão - e esta nos chama mais atenção - é o fato de que em ambas as passagens temos a confissão de que as ideias de Kant "constaram em seu trabalho"; por outro lado, elas seriam realmente determinantes e imprescindíveis à consecução do trabalho do filósofo francês? E podemos afirmar com convicção que essas leituras serão mais enfatizadas do que as de Lignac, Descartes ou Leibniz, por exemplo? Para analisarmos essas questões, iniciaremos a investigação colocando Maine de Biran em diálogo com aquele que criticou a sua interpretação do sistema kantiano.

\section{Objeções ao sistema de Ampère por Maine de Biran}

É curioso observarmos que embora Ampère critique Maine de Biran por ter uma concepção frágil e insuficiente do criticismo kantiano, ele sofra, por parte de Biran, críticas que se sustentam no criticismo kantiano. Nas "conversas" entre Biran e Ampère, Biran defende que o sistema kantiano poderia opor-se contundentemente às ideias de Ampère. Ora, admitamos que uma objeção desse tipo não caberia a quem desconhecesse totalmente a origem e os desdobramentos

\footnotetext{
${ }^{2}$ Destacamos também sua acepção do livro de Kinker, "Ensaio sobre uma exposição sucinta da crítica da razão pura".
} 
dos argumentos kantianos, independentemente da autenticidade de sua fonte. Para compreendermos de maneira clara a oposição destacada por Biran, informamos já de início que a questão censurada em Ampère trata do valor objetivo de nossos conhecimentos à forma como é defendida por este último.

Ampère (1870) distingue as relações dependentes da natureza de seus termos tal qual discernimos entre as qualidades dos corpos das relações geométricas, que seriam as mesmas tanto para um cego de nascença quanto para aquele dotado de uma visão saudável. $O$ autor (AMPÈRE ,1870) defende que as qualidades dos corpos são subjetivas e não pertenceriam aos noumenos; para ele, seria um absurdo afirmar a realidade absoluta das relações que tendem a essas qualidades e, em geral, das relações que dependem da natureza dos termos comparados. A intuição em Ampère (AMPÈRE,1870, p. 283) é denominada como “o ato pelo qual nós vemos, numa coordenação preexistente, independentemente da natureza dos elementos coordenados, o mesmo modo de coordenação e de relações de uma sequência primária". É entre os modos de coordenação independentes das coisas que Ampère coloca o espaço, a causalidade, a permanência etc. Dessa forma, para Ampère (AMPÈRE ,1870, p. 295), todos os julgamentos que repousam sobre a natureza desses modos de coordenação, e não sobre a natureza dos termos coordenados, têm a mesma necessidade que os axiomas das matemáticas, e esses modos é que são as verdadeiras leis de nossa inteligência.

Quanto a essas leis, Ampère (AMPÈRE,1870, p. 156) pergunta-se: em que esses modos de união diferenciam-se dos próprios fenômenos e por que não os realizamos? Porque não dizer que só há no corpo causas desconhecidas, que fazemos parecer extensas e em movimento sem que realmente ali estejam? Ocorre que Ampère rejeita essa hipótese em nome dos cientistas que acreditam num mundo real, desprovido de toda subjetividade e contendo apenas relações. Lembremos que Ampère é um cientista. Para ele há uma permanência e uma extensão noumênica e infinita, em que realmente se moveriam os corpos e cujas partes seriam "coordenadas por toda a eternidade conforme todas as figuras concebíveis [...] Nesta hipótese os modos de união, extensão, permanência, causalidade, movimento, os números, a divisibilidade etc, etc., só ocorreriam entre os fenômenos, pois já teriam ocorrido entre os noumenos correspondentes". ${ }^{3}$ Maine de Biran contesta veemente essa afirmação, pois seria impossível conceber um modo de coordenação que não tivesse nada de subjetivo, e não haveria necessidade de as coisas serem coordenadas fora de nós absolutamente da mesma forma que é em nosso interior. De forma concisa, o que Ampère diz é que o mundo das aparências, dos fenômenos, é o conjunto das qualidades sensíveis e suas relações; já o mundo dos noumenos constitui-se por relações racionais. Assim, se essas relações aparecessem, também apareceriam os fenômenos sensíveis. Ocorre que Maine de Biran o contrapõe, pois reconhece que essa forma de distinção entre fenômeno e noumeno que propõe Ampère já fora rejeitada por Kant.

Maine de Biran esclarece, então, a Ampère, que ao confrontar sua posição à de Kant, falo-ia pender para o lado do filósofo alemão. Parafraseando Maine de Biran, em Kant tais modos de união (coordenação) ou tais formas são inerentes ao nosso espírito de tal maneira que só podemos conceber algo por ou sob essas formas. É essa posição idealista kantiana defendida por Biran que é posta como oposição ao sistema de Ampère. Observemo-la: se a extensão tal como a apercebemos imediatamente pelos sentidos da visão ou tato é uma forma desses sentidos inerentes a sua natureza, essa forma se alastra sobre todas as coisas representadas, quaisquer sejam elas. Assim, só conhecemos verdadeiramente a existência cuja natureza ou essência nos é desconhecida, ou seja, enquanto nós não concebemos, de nenhuma forma, como essas coisas desconhecidas, essas

\footnotetext{
3 Ampère; 1870, p. 156.
} 
forças, esses elementos, podem ser coordenados de maneira a realizar em si mesmos uma extensão ou espaço absoluto independentemente de nossas concepções.

Sem desvios, o que Maine de Biran (BIRAN,1893, p. 563) pretende é demonstrar a Ampère que ele se confundiu ao acreditar que caberia ao tratamento dado à experiência a originalidade de sua hipótese àquela de Kant. Perguntemo-nos: que experiência é essa? E Maine de Biran (BIRAN, 1893, p. 563) dá a Ampère e a nós o seguinte exemplo:

\begin{abstract}
Os corpos queimam, porque há neles um princípio inflamável, todos os corpos queimam, diz Lavoisier, porque eles têm afinidade com um princípio inflamável que está fora deles. Da mesma forma todos dizem e creem que percebemos os objetos extensos porque há neles uma extensão real. Leibniz e depois dele Kant dizem que a extensão é uma forma ou um modo de coordenação que pertence ao espírito com o qual ocultamos os noumenos, as monadas etc. Lavoisier prova por uma sequência de experiências que o princípio da combustão está fora do combustível, mas qual experiência nos ensinara se os modos de coordenação dos fenômenos estão absolutamente nas coisas ou apenas no espírito que as percebe? Esta dúvida de reflexão pode ser esclarecida por alguma experiência externa? E as duas alternativas não se enquadram igualmente com os fenômenos? (apud VALLOIS, M., 1920, p. 242).
\end{abstract}

Embora essa passagem ateste uma clara defesa por parte de Maine de Biran do criticismo kantiano, não podemos nos esquecer de que o objetivo de Biran no diálogo com Ampère é o de apresentar os pontos em que o sistema kantiano poderia refutá-lo. Entendemos que o fato de Biran aderir ao sistema kantiano nesse sentido não nos serve de fundamento para corroborar a ideia de que esse sistema fundamentaria o dele. Isto posto, realocar-nos-emos de volta à direção intentando a corroboração de que a aproximação de Maine de Biran à filosofia de Kant não diferiu dos estudos aplicados por ele a outros filósofos, ou seja, que a influência de Kant sobre Maine de Biran possui, sim, um limite, e não é imprescindível à consecução de sua filosofia. Para atestarmos e demonstrarmos essa limitação propomos, a partir de agora, demonstrar as divergências entre os métodos do filósofo alemão e do francês, apresentando o que Biran considera um equívoco do sistema de Kant.

\title{
Maine de Biran e Kant: as dissonâncias
}

Embora tenhamos atestado o conhecimento (embora claramente moderado) que Maine de Biran tem do trabalho filosófico de Kant, ele encontra em seu texto, ou melhor, em seus comentadores, questões que considera relevantes. Ao ler a exposição realizada por Kinker (KINKER,1801), Biran concorda com a posição defendida pelo filósofo alemão quanto ao paralogismo da psicologia racional. De fato, admite Biran, não podemos legitimamente concluir do eu penso, da consciência que temos de nós mesmos, enquanto pensamos e sentimos a existência de uma alma substância de uma coisa pensante. Mas há uma limitação nessa acepção declarada por Biran (Obras completas, NAVILLE, Tomo I, p. 155). O filósofo francês acrescenta: "Kant toma por insolúvel o problema da psicologia racional", concluindo que há na tese kantiana uma falsa metafísica da alma, "erro que o faz preocupar-se com um problema que sequer existe". Para Biran, a questão gira em torno da seguinte ideia: alguém que investigue ou busque pela essência do eu, necessariamente ou primariamente, questiona-se sobre o que ele é, independentemente de suas sensações e de seus pensamentos, pois esse eu que pensa e sente não sabe quem pergunta, eis a questão. Assim, não se trata do raciocinar e, sim, do fato da consciência, ou seja, da consciência do eu, sujeito distinto de todo objeto e de todas as coisas que representa.

OLIVEIRA, André Renato de. Dissonâncias e ressonâncias da filosofia kantiana sobre a filosofia de Maine de Biran. Griot : Revista de Filosofia, Amargosa - BA, v.21 n.3, p.408-425, outubro, 2021. 
A essa concepção pensemos paralelamente àquela de Kant (KANT,KrV A 342 B 400) "Eu sou, enquanto pensante, objeto do sentido interno e chamo-me alma. $\mathrm{O}$ que é objeto dos sentidos externos chama-se corpo. Assim, a expressão eu, enquanto ser pensante, indica já o objeto da psicologia, a que se pode chamar ciência racional da alma[...]". Para Kant, a alma é o objeto do sentido interno sendo eu próprio com todas as minhas representações. Na filosofia de Maine de Biran, fazer do sujeito um objeto, uma coisa pensante, é alterar sua natureza. A alma, a realidade objetiva e transcendente do eu, não é o eu (essencialmente sujeito). Não podemos dizer que a alma seja o objeto do sentido íntimo como o corpo o é do sentido externo; em Maine de Biran, o sentido íntimo não tem objeto. Outra clara discordância é que, para Maine de Biran (BIRAN,Manuscrito MSS-NS 136), é falso que a apercepção simples do eu seja absolutamente vazia, como pensa Kant, e que só tomamos do eu uma noção positiva pelas percepções e sensações que o acompanham. A apercepção imediata íntima do eu puro é aquela do querer, ou seja, do esforço voluntário. "Percebemos nosso eu em si mesmo, em sua essência e independentemente de seus modos acidentais, como força". Nessa afirmação de Maine de Biran há uma clara contraposição à impossibilidade da coisa-em-si kantiana, entre outras contestações. ${ }^{4}$

Ademais, como vimos, as maiores referências de Biran sobre Kant são os comentadores deste último. Por meio deles, ele observa que Kant atribui ao homem duas formas de considerar a si mesmo. Na exposição da filosofia de Kant feita por Villers (1801), o comentador esclarece que o homem se conhece por dois meios: por um lado, por meio das formas e das categorias, como um ser sensível, como um fenômeno submetido às leis naturais; por outro, sem nenhum intermediário, como noumeno, enquanto vontade, tendo por lei a lei moral. A essa concepção, Maine de Biran (Obras, COUSIN, Tomo II p. 20) objeta que se o eu enquanto noumeno não está submetido à relação de causalidade, nada podemos conceber. Na concepção de Maine de Biran, Kant, equivocadamente, estaria sustentando que o conceito de causa, assim como todas as outras formas necessárias do nosso pensamento, não passam de uma forma pela qual a alma enxerga as coisas sem consequências para sua realidade. ${ }^{5}$ Dessa interpretação decorreria sua posição à questão da causalidade. De acordo com Biran (BIRAN, Manuscrito, MSS. NS 136), a apercepção imediata do eu seria o sentimento de uma ação e qualquer outra ação só poderia ser sentida ou apercebida como relação causal. A causalidade é a lei primeva e universal tanto do conhecimento objetivo quanto do subjetivo e está contida essencialmente nesse primeiro ponto de vista da consciência sob o qual o homem se projeta e apercebe-se como ser existente em si, independentemente de qualquer coisa e de toda impressão externa. Maine de Biran (BIRAN, Manuscrito, MSS. NS 136) é contundente ao afirmar que Kant nunca demonstrou isso, ao menos satisfatoriamente, pois é impossível a irrealidade do que nossa organização nos obriga a conceber e crer como real. Aqui, Biran defende contra Kant que não é possível que o conceito que temos de uma coisa e a coisaem-si sejam divergentes. Mesmo, que Biran reconheça a possibilidade da coisa possuir atributos que não são compreendidos, e que ao contar com outros atributos, a distinção entre fenômenos e noumenos pode ser mantida. Por outro lado, Maine de Biran (BIRAN, Manuscrito MSS NS 136) defende que é no sentimento do esforço que o eu se apercebe como é, sem perceber tudo o que é. Nesse sentido, pode-se dizer que o eu não se apercebe como noumeno, mas em si. Vallois (VALLOIS, 1920 p. 247) corretamente atesta que, para Biran, "a consciência de toda ação voluntária é também consciência de poder agir diferente, é a consciência de uma energia virtual de um poder não atualmente exercido, que evidentemente é uma realidade superior à dos fenômenos que dela resultam".

\footnotetext{
${ }^{4}$ Retomaremos este ponto mais adiante.

${ }^{5}$ Cf VALLOIS, M., 1920, p. 245.
}

OLIVEIRA, André Renato de. Dissonâncias e ressonâncias da filosofia kantiana sobre a filosofia de Maine de Biran. Griot : Revista de Filosofia, Amargosa - BA, v.21 n.3, p.408-425, outubro, 2021. 
Assim, em Maine de Biran (BIRAN, Manuscrito MSS NS 136), é pelo esforço que o eu sente-se como força. Há, objetivamente, uma força virtual, uma energia constante, embora não seja constantemente exercida; há uma causa substancial. Constata-se, nessa asserção biraniana, uma acepção muito próxima da ideia de Leibniz sobre observar os seres como forças e as forças como os únicos seres reais, do que de Kant. O comentador Vallois (VALLOIS,1920 p. 247) valida nossa afirmação destacando que "na presença do problema sobre a origem das ideias, Leibniz lhe parece ofertar uma posição preferível a de Kant". O próprio Maine de Biran (Obras completas, COUSIN, Tomo. III p. 299) sustenta que a alma é, conforme Leibniz, uma força, uma monada, e a essência de toda monada é a atividade. As ideias que estão na alma e não foram recebidas pelos sentidos são produtos dessa atividade. Chega-se, assim, a Descartes e à crítica de sua posição a respeito das ideias inatas. Em seu sistema, Descartes defende que a essência da alma é o pensamento; a alma o tem recebido como tem recebido sua existência, sem que nenhuma atividade, potência ou virtude própria a ela contribua a sua produção. Essa crítica é importante, pois é a partir dela que Maine de Biran declarará que Kant elaborou uma teoria média, teoria que trata, por um lado, das formas residentes no sujeito somente pela necessidade de sua natureza, isto é, passivamente, assim como Descartes; por outro lado, o filósofo alemão admite, como Leibniz, as virtualidades, tomando as ideias somente por sua união com as impressões recebidas. Essas formas são, efetivamente, representações apenas em união com a matéria dada. Maine de Biran rejeita contundentemente a teoria das ideias inatas, de elementos a priori, e as demais que defendem teorias similares a elas. Para Maine de Biran (Obras completas, NAVILLE, Tomo III, p. 107), elas conduzem "à morte da análise".

Contrária a isso, a proposta de Maine de Biran é fundar a filosofia sobre o sentimento do esforço. A ela temos a ideia de que toda atividade espiritual tem sua origem a partir de atividades voluntárias. Conforme o próprio Maine de Biran (Obras completas, COUSIN, Tomo II, p. 110), Kant teria ignorado a verdadeira natureza da atividade intelectual, ou seja, o esforço. Assim, embora o filósofo francês estivesse de acordo com Kant a respeito de sua distinção entre a forma, o eu e todas as noções que dele derivam, da matéria dada submetida à ação da forma, essa concordância é efêmera. Efêmera porque em Maine de Biran, a forma e a matéria só podem servir de princípio a uma verdadeira decomposição do pensamento se realizasse uma verdadeira distinção entre esses dois elementos da experiência, e não apenas uma distinção lógica como propõe Kant. Na concepção de Biran, se a forma e a matéria não podem existir separadamente na experiência e se estão frequentemente unidas, elas não passam

[...] de dois nomes distintos que exprimem dois pontos de vista particulares, sobre os quais o espírito pode conceber uma única e mesma modificação sensível, mas não a ideia de dois elementos ou duas partes realmente distintas e separadas, uma matéria, a outra formal, na qual esta modificação possa se resolver, não haveria ali decomposição verdadeira, apenas uma simples analise lógica. (Obras completas, COUSIN, Tomo II, p. $115)$.

O projeto de Maine de Biran é claro e trata de distinguir uma forma pessoal e uma matéria afetiva que possam existir uma sem a outra. A forma pessoal, consciência do eu à qual as afeições pertencem, não a acompanhariam sempre, ela se obscureceria até desligar-se. Quando a afecção passiva aumenta em intensidade a ponto de ocupar todo o espírito, ela aclara-se à medida que essa afecção se enfraquece, apresentando o eu a si mesmo, isto é, a sua própria ação. ${ }^{6}$ Ao fazê-lo, Biran acredita descobrir uma afecção sensível simples, desprovida de todas as formas da percepção, a

${ }^{6}$ Cf. Obras Completas, Cousin Tomo II, p. 116; Obras completas, Naville, Tomo I, p. 204.

OLIVEIRA, André Renato de. Dissonâncias e ressonâncias da filosofia kantiana sobre a filosofia de Maine de Biran. Griot : Revista de Filosofia, Amargosa - BA, v.21 n.3, p.408-425, outubro, 2021. 
saber, das formas pessoais (ou próprias) e das formas de tempo e espaço, atribuídas por Kant à sensibilidade. Essa afecção simples está acima da impressão orgânica, mas abaixo da sensação, pois a sensação não é simples e, sim, composta por uma matéria afetiva variável e múltipla, que nada mais é do que a afecção sensível simples e de uma forma constante idêntica, totalmente fundada no sujeito eu e na apercepção de seus próprios atos ou sentimento de seus resultados. ${ }^{7}$ Constata-se, em Biran (Obras completas, COUSIN, Tomo. II, p. 117), que mesmo que esse seja sempre um composto, os elementos da sensação não estão constantemente misturados num mesmo grau: "Algumas vezes a matéria que chamo afecção simples está bem próxima de ser isolada da forma aperceptiva, outras vezes, é esta última que é pura". De maneira direta, Maine de Biran intenta demonstrar que Kant não notou que na experiência interna a forma e a matéria se distinguem uma da outra como um fato se distingue de outro fato, e que mesmo na sensação, em que estão realmente sempre unidas, observa-se sua tendência à separação. Vallois (VALLOIS, 1920 , p. 250) sustenta que essa distinção da matéria e da forma corresponderia àquela do abstrato passivo (abstractus) e do abstrato ativo (abstrahens) que Maine de Biran frequentemente cita, e em favor dos quais ele invoca a autoridade de Kant que, na Dissertação de 1770, "ele reconheceu e exprimiu a mesma distinção, embora não tenha sempre permanecido fiel a ela" ${ }^{8}$ Tal aceitação e sua respectiva contestação são sustentadas dentro dos seguintes parâmetros: Kant distinguiu, por um lado, os conceitos que temos abstraído dos dados empíricos e que exprimem propriedades gerais comuns a vários objetos comparados; por outro lado, temos os conceitos intelectuais puros, que derivam da mesma natureza de nosso entendimento e são abstração de todo elemento empírico. Embora Maine de Biran tenha retido essa distinção, o filósofo francês afasta-se de Kant ao defender que:

[...] não retiramos das coisas, por abstração e generalização nossa noção de força [...], mas sim realizando abstração de todos os objetos exteriores, então a encontramos em nós próprios, pois percebemos imediatamente nossa própria força como constituindo a essência de nossa personalidade, pois a concebemos como infinitamente reproduzida pelas coisas, repetida em todos os objetos, "é assim que a noção torna-se universal sem jamais ser geral". É evidente a noção de eu e de todos aqueles que dele derivam, tais como: a noção de substância, de identidade, de unidade etc. que Maine de Biran chama de noções reflexivas. (Vallois, 1920, pp. 250-251).

Assim, a noção de eu é, em Biran, uma noção reflexiva e não uma noção geral, pois esta se distancia cada vez mais da realidade enquanto é mais abstraída; já uma noção reflexiva, ao contrário, concebida na pureza por essa abstração que consiste em afastá-la de tudo o que é exterior, exprime uma realidade concreta e mais lapidar. ${ }^{9}$ Observemos que essa posição difere consideravelmente da de Kant, pois, para este último, a realidade empírica consiste na união da forma e da matéria, e para o filósofo alemão nem a forma sem a matéria, nem a matéria sem a forma, tem qualquer realidade em nossa experiência, por isso as noções reflexivas, os conceitos intelectuais em si mesmos são vazios. Daí advém a contestação de Maine de Biran, que afirma haver um equívoco por parte de Kant quanto à atividade intelectual, pois o filósofo alemão não teria compreendido corretamente o verdadeiro sentido da distinção que ele próprio tinha indicado antes.

Verificado na filosofia de Maine de Biran (Obras completas, NAVILLE, Tomo I, p. 204) que as noções reflexivas de força, de causa, de unidade, de identidade e de substância encontram

\footnotetext{
${ }^{7}$ Cf. Obras completas, Cousin, Tomo II, p. 116.

${ }^{8}$ Cf. Obras completas, Naville, Tomo I, p. 306.

${ }^{9}$ Cf. Obras completas, NAVILLE, Tomo II, p. 373.
} 
no sentimento do esforço seu modelo, e que tal derivação das noções reflexivas partiriam de um fato primitivo sem ir além dos limites da experiência interior, contrapomo-la à teoria kantiana, na qual as categorias, assim como as formas da sensibilidade, seriam propriedades permanentes dos noumenos interiores. Sobre essa oposição enfatizamos a afirmação do comentador Vallois (VALLOIS,1920, p. 252): “É imprescindível investigar como Maine de Biran explica a universalidade dos princípios do conhecimento, que nenhum fato da experiência poderia conforme Kant explicar". De fato, é imprescindível, pois Maine de Biran chega à concepção de que os racionalistas - em especial os kantianos - objetar-lhe-iam a concepção das noções de causa, substância etc. serem tiradas de um fato. Desse ataque, Biran defende-se da seguinte forma:

\begin{abstract}
Kant e os metafísicos racionalistas que ele tem inspirado são partidários das noções de causa, de substância, mas parecem não terem suspeitado que estas noções pudessem ser direcionadas a qualquer fato primitivo, além do mais, eles descartam qualquer meio a um tal fato original ou a uma experiência interior, reduzindo-o a oferecer apenas uma base contingente à ciência, cuja toda certeza deve de acordo com eles repousar sobre os princípios a priori. Assim, eles têm sacrificado constantemente a evidência deste fato àquele da razão, e esforçam-se em tomar uma certeza puramente lógica por uma certeza metafísica. Que um conhecimento seja universal e necessário, não quer dizer que ele não possa ser um produto da experiência, é nisto que a filosofia de Kant parece-me ser totalmente falha. (BIRAN, Ciência e psicologia, ed. Bertrand, p. 173; Manuscrito MSS. NS 133).
\end{abstract}

Isto posto, torna-se possível defender que, embora Maine de Biran reconheça a veracidade do argumento de Kant, pois, realmente, é impossível atingir o universal pelo geral, ele também se opõe ao filósofo alemão, demonstrando que a indução lógica ou a generalização não é suficiente para dar-nos um conhecimento universal. Eis a originalidade e a genialidade da objeção de Maine de Biran.

Kant não percebeu que há uma indução psicológica que não repousa sobre um grande número de observações e que somente uma seria o suficiente para fundamentá-la. ${ }^{10}$ Essa indução consiste em transferir ao não eu a causalidade do nosso eu, que captamos em cada percepção de nós mesmos. Logo, a universalidade do princípio de causalidade é a consequência dessa indução. ${ }^{11}$ Noutras palavras, é no sentimento do esforço, que também é o de uma resistência, que percebemos essa resistência, e é na percepção de força que se constitui a realidade do nosso eu. Nas palavras de Vallois (VALLOIS, 1920, p. 253), “a essência do eu consiste em sua própria força, o não-eu é essencialmente o termo de resistência que se opõe a esta força, isto é, outra força". Disso advém que a substância de um corpo é "uma simples força individual, concebida como a essência de tudo o que chamamos corpo, a saber, a faculdade de resistir a nosso esforço, ou de reagir contra nossa própria força constitutiva" (Obras completas, NAVILLE, Tomo II, p. 373). A essa questão atrelamos a da causalidade, pois, para Maine de Biran (Ciência e psicologia, pp. 235-255), a causalidade é entendida como a "relação de um fenômeno que se inicia com a força atuante", e sendo a sequência dos fenômenos necessária à ação das forças, pode-se concluir que a ordem dos fenômenos é uma ordem necessária, logo constante, ou seja, conforme as leis universais com o princípio de causalidade como os físicos a concebem. ${ }^{12}$ Maine de Biran (Obras completas, COUSIN, Tomo IV, p. 401) defende que as forças devem ser imateriais e que os "fenômenos não são fundamentalmente nada mais do que os resultados mais gerais da ação destas forças necessariamente concebidas a forma do eu como imateriais e, portanto, imutáveis".

${ }^{10}$ Cf. VALLOIS, 1920, p. 253.

11 Cf. VALLOIS, 1920, p. 253.

12 Cf. VALLOIS, 1920, p. 254.

OLIVEIRA, André Renato de. Dissonâncias e ressonâncias da filosofia kantiana sobre a filosofia de Maine de Biran. Griot : Revista de Filosofia, Amargosa - BA, v.21 n.3, p.408-425, outubro, 2021. 
Para defender tal concepção de causalidade, Maine de Biran acomete a teoria da causalidade de Hume. Nesse sentido, parece novamente estar próximo a Kant. "Parece", porque essa aproximação limita-se à crítica ao filósofo escocês. Embora Biran concorde que a relação causal não seja analítica e que o princípio de causalidade ultrapasse o alcance da lógica, quando busca estabelecer uma ligação entre os dois termos dessa relação, ele os considera como duas coisas isoladas, dois fatos realmente separados um do outro. Observemos a distinção: Kant afirma a necessidade de uma síntese, considerando que esses dois termos seriam dois fenômenos nos quais o conceito de um não implicaria logicamente no do outro, mas a análise dos conceitos não pode descobrir entre eles uma ligação que deixe claro que um dos fenômenos sempre acompanha o outro. Para Kant, a síntese deve, de alguma forma, compensar a impotência da análise, que é o objeto da lógica geral e, por isso, as formas da síntese, as categorias, corresponderiam às diversas formas lógicas do julgamento indicadas pela lógica geral, e seu objeto pela lógica transcendental. ${ }^{13}$

\begin{abstract}
Assim Kant é conduzido a conceber a ligação sintética da causa e do efeito por sua analogia com a ligação do antecedente e do consequente no julgamento hipotético. Este conceito de uma dependência entre as coisas análogas à dependência do antecedente e do consequente no julgamento hipotético, se nós o aplicarmos à sucessão dos fenômenos, conceberemos que "os fenômenos do tempo passado determinam toda existência no tempo que segue, e que os fenômenos deste último só teriam lugar como acontecimentos enquanto que aqueles do tempo anterior determinam para eles uma existência no tempo, isto é, fixam segundo uma regra. É assim que a ordem objetiva da sucessão dos fenômenos é definida, visto que a ordem do tempo absoluto, onde o instante que precede determina necessariamente aquele que se segue, sendo transportado aos fenômenos. (VALLOIS, 1920 , p. 256).
\end{abstract}

Desse modo, o objetivo do princípio de causalidade seria o de demonstrar que o princípio da razão suficiente é o fundamento da experiência possível, ou como é dito por Kant (KANT, KrV A201): “Assim, o princípio da razão suficiente é o fundamento da experiência possível, ou seja, do conhecimento objetivo dos fenômenos, quanto à relação dos mesmos na sucessão do tempo". $\mathrm{O}$ filósofo alemão propõe que a sucessão dos fenômenos não pode ser representada como objetiva, que o lugar dos fenômenos no tempo absoluto só poderia ser determinado na medida em que os fenômenos que os precedesse fossem considerados tão determinantes quanto aqueles que seguem um princípio que estabelece suas consequências. Dessa forma, a necessidade lógica conservaria uma significação objetiva, ainda que a necessidade objetiva (a necessidade das relações que constituiriam a objetividade dos fenômenos que eles contêm) não pudesse ser analítica. ${ }^{14}$

Por outro lado, para Maine de Biran (BIRAN, Manuscrito MSS. NS 135), a causalidade possui três termos, a saber: a causa, o efeito e a ação pela qual um produz o outro. Seu desejo é estabelecer contra Hume uma necessidade de fato, concebida após o sentimento de uma ligação indissolúvel entre o esforço e a resistência. Já Kant nega a necessidade racional, cognoscível $a$ priori da causalidade defendida por Hume.

Essa concepção biraniana entre esforço e resistência faz surgir o eu, questão que nos conduz a compará-la à espontaneidade do sujeito kantiano. Maine de Biran (Obras completas, COUSIN, Tomo II, p.105) compreende a teoria kantiana das funções do sujeito do conhecimento de uma forma que a torna totalmente inadmissível para qualquer um que, como ele, entenda que todo nosso conhecimento se funda na realidade sobre uma ação do sujeito, que é ele próprio um fato da experiência. Biran, ainda orientado pela leitura de Kinker, entende que Kant deseja fundar o

${ }^{13}$ Cf. VALLOIS, 1920, p. 256.

${ }^{14}$ Cf. Vallois, 1920, p. 257.

OLIVEIRA, André Renato de. Dissonâncias e ressonâncias da filosofia kantiana sobre a filosofia de Maine de Biran. Griot : Revista de Filosofia, Amargosa - BA, v.21 n.3, p.408-425, outubro, 2021. 
conhecimento sobre as formas que regulam a própria experiência e que, como tais, devem localizar-se noutros lugares além da experiência. Por decorrência dessa interpretação, Maine de Biran (Obras completas, COUSIN, Tomo II, p. 110; IV, p. 368) defende que o paralogismo denunciado por Kant ( $\mathrm{KrV})$, que consiste em passar dos conceitos ou dos fenômenos aos seres ou noumenos, está, de algum modo, comprometido pelo próprio Kant, pois quando este último coloca em nós a atividade reguladora da experiência acreditando "sanar o problema das existências com a ajuda das categorias ou formas inerentes à alma ou noumeno pensante; colocando em equidade as propriedades permanentes do noumeno interior às da categorias e as das formas", comete um equívoco que invalidaria o fundamento de seu paralogismo.

Conforme propomos neste tópico, verificamos algumas das discordâncias entre Maine de Biran e Kant. Verificamos, também, que a leitura de Maine de Biran sobre a filosofia de Kant é imprecisa em vários pontos, mas, por outro lado, as observações e críticas levantadas por ele têm seus méritos e nos auxiliam a entender seu projeto filosófico em sua originalidade e em demonstrar seu afastamento do sistema kantiano. A fim de ampliarmos nossa tese e nos aprofundarmos um pouco mais nas críticas feitas por Biran a Kant, propomos pontuá-las com maior rigor a partir de agora.

\section{Considerações finais: as críticas de Maine de Biran}

Antes de discorrermos sobre as objeções realizadas por Maine de Biran a partir deste ponto, advertimos que as posições kantianas defrontadas por ele não seguem necessariamente uma lógica textual coerente, ou seja, há alguns "saltos temáticos". Contudo optamos por seguir essa concatenação, se assim podemos defini-la, respeitando a originalidade argumentativa das críticas realizadas pelo filósofo francês. ${ }^{15}$

Isto posto, Maine de Biran (Obras escolhidas, GOUHIER, 1942, p. 213) contesta Kant por supor que o eu que apercebe a si mesmo como noumeno está tanto fora da relação de causalidade quanto da de substância. Com essa afirmação iniciamos este tópico, considerando, então, essa posição como questão diretriz. A fim de pensá-la temos de recapitular que Maine de Biran orientase fundamentalmente pelos textos dos comentadores Kinker e Villers, e será a partir deles que fundamentará sua contraposição. Será, por meio de uma passagem da exposição deste último, que Biran fundamentará sua crítica sobre a tese da apercepção de si kantiana. Observemo-la:

O homem é um ser em si, uma coisa real, um noumeno; é nesta maneira própria de ser (é necessário dizer este ser próprio) que o homem pode aperceber-se imediatamente na consciência íntima. Não havendo qualquer necessidade de um intermediário, nem sentidos... O eu puro e fundamental é o único dos noumenos que é dado ao homem considerado originalmente ${ }^{16}$ e sem modificações. [...]. Qualquer um que se volte ao âmago da vida e do sentimento do homem, encontra ali esta maravilha, esta existência interior que não é a cognição, mas sim a base de toda cognição, de toda existência trazida do exterior. [...] $\mathrm{O}$ homem tem duas formas de considerar a si mesmo, a saber pelo o auxílio de sua própria sensibilidade e por seu entendimento; ele torna-se assim por si mesmo um objeto percebido e concebido como qualquer outro, um fenômeno, uma parte qualquer da natureza sensível. Seu sentido externo (aquele da intuição) da margem às percepções que

\footnotetext{
15 Não pretendemos delongar-nos à problemática dos textos biranianos, mas sabe-se que são um conjunto de manuscritos recolhidos (salvo algumas exceções publicadas pelo próprio Maine de Biran, como: "A influência do hábito sobre a faculdade de pensar"; "Exame das lições de filosofia do Sr. Laromiguière" e "Exposição da doutrina de Leibniz". Ademais, temos as edições compiladas de Tisserand, P. a de Naville, E. e a de Gouhier, H., ou seja, falamos de manuscritos e anotações que passaram, no decorrer dos anos, por "várias mãos".

16 Acréscimo nosso, no original d'envisager à nud.
}

OLIVEIRA, André Renato de. Dissonâncias e ressonâncias da filosofia kantiana sobre a filosofia de Maine de Biran. Griot : Revista de Filosofia, Amargosa - BA, v.21 n.3, p.408-425, outubro, 2021. 
ele tem de si mesmo; seu sentido interno lhe dá a sucessão sem extensão; assim ele adquire uma alma e um corpo. [...]. Seu entendimento faz dele uma substância, uma causa, um efeito, etc., tal é o homem fenomênico, o homem sensível, concebido, conhecido, demonstrado pela cognição humana. (VILLERS, 1801, pp. 364-365-366).

Tomando essa passagem como referência, Maine de Biran (BIRAN,1942, p. 214) destaca, por outro lado, as duas formas do homem considerar-se, a saber, como objeto ou fenômeno pelos sentidos externos da intuição (como sujeito eu ainda fenomênico, se assim quisermos) e pelo sentido íntimo de sua individualidade, que é aquele do esforço, pelo qual ele se reconhece antecipadamente como uma força noumenal, independente, atuante sobre os órgãos que lhe obedecem. Contudo é neste último que estaria a origem da percepção, de toda a existência, e a do próprio entendimento. Nas palavras do próprio Maine de Biran:

Kant coloca o entendimento e todas as faculdades ou formas da cognição fora deste sentido íntimo da individualidade, ele entende que o eu puro apercebe instantaneamente seu ser noumenico, sem que nenhuma das formas que supostamente devem pré-constituir sua natureza ou introduzir-se em sua essência contribuam para esta apercepção interna imediata; isto não é admitir que a alma abstraia o essencial de seu ser daquilo que a constitui precisamente antes de toda experiência, e mais, como conceber este ser abstrato senão como um signo? (BIRAN, 1942, p. 242).

Maine de Biran (BIRAN,1942, p. 215) questiona: seria, então, "a alma uma substância, uma causa, ela se aperceberia como um eu puro, estranha a tudo o que ela é, e a tudo que contem em si mesma, não sendo nem substância nem causa; estranha a todo atributo e a todas as leis de sua natureza". Biran (BIRAN,1942, p. 215) entende que a explicação dada pelo "autor a esta forma de considerar e/ou expor o eu puro é justamente o que aniquila sua própria concepção". Observemos:

\begin{abstract}
Eu sou, diz o autor, um ser atuante: portanto, de uma ordem das realidades que advém do eu, que tem sua fonte e seu princípio em mim. A soma de minhas ações e aquela dos atos de minha vontade que as determinam, formam um sistema de coisas, de modos ou fatos, determinados ou criados apenas por mim. Os objetos de minha cognição me são dados, eles chegam ao eu sem que eu possa os repelir (isto não é exatamente verdade, há uma atividade da qual depende a cognição). ${ }^{17}$ Eu não posso criar novos objetos. Ao contrário, eu produzo, posso alterar os resultados de minha atividade, sua realidade advém apenas do eu, esta realidade parte do cerne de meu ser; ela é a mesma que aquela de meu sentimento íntimo, enquanto que aquela a que atribuo as coisas, parte do exterior para chegar ao cerne de meu ser, o eu não é suficiente para produzi-lo, para tal é necessário o eu e as impressões externas que recebo das coisas. Minhas ações e minha vontade que a determina são o que me garante a realidade de meu ser. [...]. Eu ajo e eu desejo, eis o que é para mim o mais real de tudo que posso conhecer e demonstrar fora de mim. (VILLERS, 1801, pp. 367-369).
\end{abstract}

De maneira distinta, a apercepção imediata interna do eu puro não é senão aquela de um querer e de um ato primitivo para Biran; o querer e a ação só podem ser percebidos ou sentidos sob a relação primeva de causa e efeito. A causalidade é a lei primária e universal tanto do conhecimento subjetivo quanto do objetivo, e está contida essencialmente nesse primeiro ponto de vista da consciência, pelo qual o homem apercebe-se como ser individual em si. ${ }^{18}$ Conforme Maine de Biran (BIRAN,1942, p. 216), "todo o sistema de nossa cognição apoia-se sobre o fato

\footnotetext{
17 Acrescido por Maine de Biran, 1942, p. 215.

18 Cf. Maine de Biran; Gouhier, 1942, p. 216.
}

OLIVEIRA, André Renato de. Dissonâncias e ressonâncias da filosofia kantiana sobre a filosofia de Maine de Biran. Griot : Revista de Filosofia, Amargosa - BA, v.21 n.3, p.408-425, outubro, 2021. 
primitivo, e Kant não poderia e nem deveria separá-los, isolando um do outro, os dois sistemas intelectual e moral partem da mesma fonte e nenhum deles pode ser concebido sem o outro". Ainda imersos nesse contexto, deparamo-nos com outra passagem de Villers (VILLERS,1801, p. 370) analisada por Biran (BIRAN,1942): “O que se manifesta neste eu íntimo que deseja e age? O que eu descobrirei ali? [...] Descobrirei que o eu íntimo e sua faculdade de desejar não estão de forma alguma submetidos às leis da faculdade de conhecer; que minha vontade independente e espontânea é um princípio ativo por si mesmo". A isso, Maine de Biran (BIRAN,1942, p. 216), embora concorde que o eu e a vontade não estão submetidos às leis da faculdade de conhecer, responde que "trata-se de saber se estas leis são ou não subordinadas às outras, de tal forma que não há conhecimento possível sem eu, sem atividade, sem querer [...]". Biran sustenta claramente que o fundamental da questão é se a cognição é a condição primária, uma vez que é ela que constitui unicamente o sujeito que conhece enquanto age e deseja, e tudo o que pertence a esse sujeito, por conseguinte, é inseparável dele. Não obstante segue a passagem: "A consciência íntima do eu coloca-me em contato com uma coisa-em-si, com a única de todas as coisas em si que eu posso apreender ou captar" (VILLERS, 1801, p. 371). Ocorre que, para Maine de Biran (BIRAN,1942, p. 216), é essa "consciência íntima ou eu, que serve de fundamento a todas as noções que podemos ter das coisas em si ou dos seres que são causa dos fenômenos (qualquer que sejam estes fenômenos) provando cada vez mais a subordinação donde estão as leis do conhecimento, em relação ao fato primitivo que constitui o eu".

Por isso, Maine de Biran (BIRAN,1942, p. 216) sustenta que "a filosofia de Kant eleva um abismo entre o conhecimento e a realidade das coisas; entre a apercepção do eu, o único dos noumenos que poderia ser conhecido, e todas as existências externas sobre as quais encontramonos num ceticismo necessário". O próprio Maine de Biran (BIRAN,1942, p. 216) confessa: "Procurei preencher este abismo". Destacamos que, dentre as dificuldades em preenchê-lo, contamos, em especial, com a questão da "atemporalidade"; para Biran, o eu não está nem no tempo nem fora dele, ele é considerado o "primeiro anel". ${ }^{19}$ Num dos diálogos com Ampère, Maine de Biran (BIRAN, Diálogos com Ampère, 8 de janeiro de 1816) argumenta que não é o fato primitivo que proporcionaria o eu puro noumenal, mas, sim, a reflexão sobre esse fato, a consciência que se debruça sobre si mesma; "Eu digo agora que é a consciência de uma força virtual, de uma energia livre que exercer-se de outra forma. A alma apercebe-se como é sem perceber tudo o que é, isto é, tudo o que ela é capaz enquanto força, pois assim ela conhecerá o infinito". Novamente, cabe aqui a transcrição da passagem de Villers (1801), donde parte Maine de Biran:

Há uma coisa em si, um noumeno que se manifesta ao homem, e é ele próprio. Ele apercebe-se imediatamente pelo sentido íntimo de sua consciência enquanto ser ativo (eu digo ser livre),${ }^{20}$ ele percebe seu ser de um modo totalmente distinto daquele pelo qual percebe os objetos externos, sem intermédio da sensibilidade, de seu entendimento de sua cognição, ou seja, das leis do espaço, do tempo, das categorias. (VILLERS, 1801, p. 404).

Ao que Maine de Biran (BIRAN,1942, p. 217) questiona ser necessário que o eu primitivo aperceba-se sem o intermédio dessas faculdades ou leis da cognição, uma vez que "é esta apercepção imediata que é a origem ou o princípio do qual depende estas leis, e que ele não depende de nenhuma delas; fora do eu não há tempo, logo o eu primitivo está fora da lei do tempo, ele é causa, portanto sua apercepção não depende da lei de causalidade, logo ele próprio é o seu próprio

\footnotetext{
19 Letra do próprio Maine de Biran.

20 Acrescido por Biran.
}

OLIVEIRA, André Renato de. Dissonâncias e ressonâncias da filosofia kantiana sobre a filosofia de Maine de Biran. Griot : Revista de Filosofia, Amargosa - BA, v.21 n.3, p.408-425, outubro, 2021. 
fundamento". E segue: "Nós poderíamos ter o sentimento de causa, de força atual na relação primitiva do esforço voluntário com seu resultado atual, e este sentimento constitui sua personalidade simples, um sentimento do eu distinto das modificações sensíveis e de qualquer outra existência...". Conforme Maine de Biran (BIRAN, 1942, p. 217), esse modo de personalidade do homem é inerente não só ao sentimento de uma força atual, produtiva e determinada de tal modo, mas muito mais e, principalmente, ao sentimento de um poder agir ou de uma força virtual que poderia exercer-se de outra maneira. "Entendemos diz, Kant por ser intelectual, uma coisa que não pode ser apercebido por nós, embora tenhamos dela recebido alguma impressão, nós apenas a concebemos negativamente, dizemos não o que é, mas o que não é, e simplesmente damos a entender que um ser intelectual não é um simples fenômeno" (BIRAN, 1942, pp. 217-218).

Para pensar satisfatoriamente tal posição de Kant, Maine de Biran (BIRAN,1942, p. 218) propõe que, primariamente, devemos nos atentar e "entender bem o verdadeiro valor dos termos aperceber e conceber...". E o filósofo francês nos explica esse valor da seguinte forma:

\begin{abstract}
Quando dizemos que um ser intelectual (uma coisa ou uma causa da qual recebemos impressões) não pode ser apercebido por nós, entendemos ordinariamente que tal ser causa não é susceptível de ser sentido, imaginado ou concebido com o auxílio dos sentidos externos tais como: a visão e o toque, aos quais somos inclinados a relacionar todas as nossas ideias, porque seus efeitos predominam sobre qualquer outro sentido na organização humana; mais de que ser, a força ou a causa de que sinto a impressão não é susceptível de ser assim imaginada ou concebida à forma de um objeto visível ou tangível, por conseguinte, realmente não se segue disto que ele não possa ser apercebido ou concebido auxiliado por um sentido próprio, o mesmo a que se prende o sentimento íntimo de nossa individualidade pessoal idêntica, ou àquele de nossa atividade. É desta forma que concebemos tudo o que chamamos força, causa produtiva ou eficiente, e nestas concepções ou noções o sentido de nossa atividade pode funcionar tanto como aquele da visão quanto o do tato funciona nas ideias relativas aos objetos externos. Não somos forçados a conceber os seres intelectuais sem as ideias negativas, além disso sabemos que eles não são fenômenos; estamos mais seguros que estes são seres reais permanente às forças ativas a forma de nosso eu. (BIRAN, 1942, p. 218).
\end{abstract}

É sob essa perspectiva "distintiva" que Maine de Biran (BIRAN,1942, p.219) passa a questionar a impossibilidade atribuída por Kant em se considerar uma coisa tal como é em si mesma. $O$ filósofo francês questiona: o que é ser-em-si? O que é conceber uma coisa- em-si? E qual é a forma de tal concepção? À concepção de coisa-em-si kantiana, Maine de Biran (BIRAN, 1942, p. 219) opõe-se, sustentando que a "força atuante que constitui o eu é a única que pode-se dizer existir em si, ser apercebida, e enquanto tal, é em-si-mesma". Fundamentado por essa concepção, Maine de Biran (BIRAN,1942, p. 220) sustenta ser um erro Kant recusar ao entendimento o poder de conceber algo além dos objetos sensíveis, isto é, fora das qualidades que constituem esses objetos sensíveis, que as coisas em si mesmas seriam desconhecidas pelo entendimento. Atrelamos a sua recensão sobre a questão da incognoscibilidade da coisa-em-si em Kant, a análise biraniana sobre o sujeito, a partir da concepção do cogito cartesiano. Observemos a passagem a seguir e a justificativa de tal aproximação.

A existência das coisas às quais as ideias da razão (as noções) são relativas, é impossível provar. De fato, estas ideias (alma, universo e Deus), isto é, as causas dos fenômenos, e a totalidade destes fenômenos são as condições primárias dos princípios geralmente superiores a todos os outros princípios; não dependentes de nenhuma outra condição, é impossível a razão os adquirir através da dedução ou conclusão legítima. (KINKER; 1801, p. 86).

OLIVEIRA, André Renato de. Dissonâncias e ressonâncias da filosofia kantiana sobre a filosofia de Maine de Biran. Griot : Revista de Filosofia, Amargosa - BA, v.21 n.3, p.408-425, outubro, 2021. 
É disso que, conforme Maine de Biran (BIRAN, 1942, p. 220), segue o erro do primeiro princípio de Descartes, "que pretende deduzir o ser absoluto da alma, ou a ideia de uma causa incondicional do fato do pensamento ou da existência relativa do eu individual". A origem de todo equívoco, de acordo com Maine de Biran (BIRAN, 1942, p. 220), é que Descartes não percebeu que se o absoluto não fosse dado imediatamente na relação primitiva que constitui o fato primitivo da consciência, “o espírito não poderia ser erigido por nenhum raciocínio ou procedimento lógico artificial à concepção desse absoluto, e este se sentiria pensar por toda a eternidade sem ter a menor noção de uma coisa pensante e de uma substância cujo sentimento atual e positivo da existência do eu é um atributo ou predicado".

\begin{abstract}
Os três incondicionais aos quais a razão se eleva embora não possam ser dados pela experiência e nem provados ou demonstrados apodictamente, não são, contudo, quimeras; pelo contrário estes são dados que tendem essencialmente a disposição natural ou a forma invariável de nossa razão, e se nós não o pudermos realizá-los ou se a existência dos objetos tal qual a razão os considere em suas ideias, não possam ser rigorosamente demonstrado pela falta de princípios (dados) pelos quais eles podem ser derivados; esta impotência é subjetiva e pertence às leis de nossa cognição, assim os filósofos de todas as épocas esforçam-se para chegar a demonstração da realidade das ideias ou das noções em questão. (KINKER, 1801, p. 89).
\end{abstract}

Biran (BIRAN,1942, p. 221) destaca que é exatamente por tentar demonstrar a realidade do que é sentido ou conhecido primitivamente e necessariamente como real que os filósofos travaram num círculo de paralogismos e erros; inclui-se nisso o próprio Kant.

\begin{abstract}
A concepção de nossa alma ou do eu pensante, a concepção do universo e de Deus, todos derivados das três formas de nosso julgamento, são tornados três ramos diferentes de uma ciência chamada metafísica (que não passa da aplicação necessária da nossa razão) a saber, ciência da alma, psicologia, ciência do universo cosmologia e a ciência de Deus teologia [...] Cada uma destas ciências pretensas apropria-se tanto de certas proposições quanto das conclusões tiradas de suas premissas; mas estas premissas as quais estas conclusões se relacionam pertencem à essência de nossa cognição e ao seu uso subjetivo, bem como as formas da sensibilidade e do entendimento. [...] Donde segue que as conclusões enquanto tendem a estabelecer a realidade objetiva das ideias metafisicas não passam de joguetes da razão e sofismas, cuja ilusão domina os maiores espíritos. (KINKER; 1801, pp. 90-91-92).
\end{abstract}

Maine de Biran (BIRAN, 1942, p. 222) aclara que ao aplicarmos nossa razão às crenças necessárias, observamos que a própria necessidade subjetiva torna-se uma prova legítima da realidade do objeto pensado ou concebido como real, pois como poderíamos supor que estamos numa ilusão perpétua e donde viria a ideia de uma realidade oposta à aparência, de uma verdade oposta à ilusão e ao erro, "se o que acreditamos ou pensamos como real e verdadeiro fosse na verdade ilusório ou destituído de realidade objetiva; apenas por isso cremos e pensamos conforme as leis de nosso espírito". Parafraseando Biran, independentemente do que quer que façamos, só poderemos conceber as coisas sob as relações dadas pela natureza dessas coisas combinadas com a natureza do nosso espírito, de suas faculdades, pois é necessário que essas faculdades intervenham de alguma forma para que algo seja conhecido ou concebido. Conforme Maine de Biran (BIRAN, 1942, p. 223), “como poderíamos induzir que o conhecimento é totalmente subjetivo, ou que não haveria nos objetos nada além do que acrescentamos a ele, sem que o que eles realmente são em si mesmos possa agir de alguma forma à maneira pela qual o concebemos". Eis como Maine de Biran compreende a questão da realidade absoluta e das formas do nosso espírito: 
Todas as dificuldades levantadas pela escola de Kant sobre a realidade absoluta oposta as formas do nosso espírito, que se supõe não ter qualquer afinidade com as coisas como são, tendem a forma de conhecer o princípio de causalidade, ou a questão de saber se este princípio tem apenas um valor subjetivo, ou se ele não traz mais consigo uma realidade objetiva. O sentimento do eu sendo idêntico aquele da causa eficiente que começa o movimento e que se sente como um poder permanente de agir; enquanto não exerce nenhuma ação determinada, trata de saber se esta força ou este poder de agir inseparável da existência do eu tem uma realidade puramente subjetiva como o eu atual sentido ou se ele não tem ao mesmo tempo uma realidade objetiva como força absoluta permanente invariável enquanto que seus modos de atividade se sucedem e variam, ou como podem se exercer de uma forma totalmente diferente de sua determinação atual: de fato, se quando o eu age ele tem a consciência do poder agir de outra forma, esta consciência de uma energia virtual ou de um poder não exercido de imediato compreende evidentemente uma realidade superior ao fenômeno ou uma força, uma causa em si, diferente do modo de exercício atual e determinado desta força. (BIRAN, 1942, pp. 223-224).

Ademais, Maine de Biran (BIRAN, 1942, p. 224) ressalta: “Quando eu sinto uma afecção como efeito de uma causa ou força que não sou eu, tenho uma concepção ou noção de coisa totalmente distinta, seguramente da sensação ou do fenômeno transitório". Essa noção considerada por Maine de Biran (1942), seja como primitiva ou como uma indução rápida fundada sobre o fato da consciência, é sempre proveniente de uma lei do nosso espírito, mas ela, declara o filósofo francês, "não teria também algum valor subjetivo?". Maine de Biran prossegue:

Não se trata de provar a incompatibilidade natural que há entre uma noção fundada sobre
as leis de nosso espírito e a realidade objetiva da coisa a qual corresponde uma tal noção,
ou a impossibilidade de um acordo perfeito entre o que é em si realmente e o que nosso
espírito concebe e acredita ser real após sua constituição. Trata-se de mostrar como ao
sentir uma impressão passiva, sou obrigado por minha natureza de ser inteligente,
considerar que há fora de mim uma causa, ou uma força real que a inicia: Segue-se
primeiramente que esta força não é como eu a tenho concebido ou acreditado. (BIRAN,
1942, p. 224).

Incorre que, de acordo com Biran (BIRAN, 1942, p. 224), Kant toma como ilusão essa sequência de conclusão pela qual passamos, da concepção do sujeito pensante à existência determinada e absoluta desse sujeito. Maine de Biran (BIRAN, 1942, p. 224) parece corroborar a posição kantiana inicialmente, declarando que "ele tem razão, se verdadeiramente nós desejamos passar da concepção ou noção de uma realidade absoluta em si mesma ou independente do todo sentimento ou concepção, concluindo o ser absoluto da concepção dada como premissa (a forma de Descartes, eu penso, logo eu existo como coisa pensante)". Mas Biran segue nos impossibilitando a aproximação ao destacar que: “[...] a dificuldade se esvanece se, ao invés da razão, nos limitarmos ao fato da consciência como contendo indivisivelmente a dupla realidade subjetiva e objetiva". Verifiquemos e atestemos tal posição na sequência do argumento de Maine de Biran (BIRAN,1942, p. 224): "Encontramos de fato em nós, ou no sentimento de um esforço voluntario, a concepção de uma força atuante ou de uma causa real, que enquanto sentida possui um valor subjetivo; a força ou a própria causa substancial tem um valor objetivo, na medida em que ainda é constantemente e igualmente força virtual, e energia constante quando não está sendo exercida de forma determinante". Para Biran, a concepção transcendental dessa força absoluta é que constitui a essência ou a permanência da alma, essa inseparável da primeira experiência, e não pode ser dito vir ela de uma experiência repetida.

OLIVEIRA, André Renato de. Dissonâncias e ressonâncias da filosofia kantiana sobre a filosofia de Maine de Biran. Griot : Revista de Filosofia, Amargosa - BA, v.21 n.3, p.408-425, outubro, 2021. 
Todas as provas da psicologia que tomam a alma por objeto tem como fundamento apenas a percepção do eu, nossa ipseidade, percepção simples e absolutamente vazia, esta percepção que, a rigor, não pode ser chamada representação - pois eu apenas concebo este eu lhe atribuindo um predicado - este não é para nós nada mais que a consciência que acompanha todas as nossas representações, mas separado de todas estas representações, ou seja, abstração realizada do ato deste pensamento, esta percepção íntima nada mais oferece do que um eu obscuro ou indefinido que não se deixa reduzir a nenhuma representação. É necessário sempre voltar-se a associação do eu com o pensamento. (KINKER, 1801, p. 96).

Em oposição, Maine de Biran (BIRAN, 1942, p. 225) argumenta que a "apercepção simples do eu ou da força atuante não é absolutamente vazio, e não tem necessidade de ser unido a nenhuma representação ou sensação determinada para reconduzir-se a nossa noção real e positiva, que tem toda a verdade e a clareza do sentimento de nossa existência individual". O que Biran quer demonstrar é que quando dizemos que a alma (eu) é uma força, não anunciamos um predicado de um sujeito, exprimimos o sujeito real tal qual o apercebemos ou o conhecemos em si mesmo, em sua essência e independentemente de todo predicado lógico ou modo acidental. Embora reconheçamos que "para assegurar a realidade da substância da alma, é necessário mais do que o conhecimento das faculdades da nossa alma, é necessário que o fundamento de nosso próprio ser fosse um dado para nós, ou seja, que nós conheçamos não o pensamento, mas o ser que pensa" (KINKER, 1801, p. 98). Maine de Biran declara:

\begin{abstract}
Para duvidar ao contrário da realidade, da substância ou da força da alma, é necessário que as sensações ou os pensamentos fossem dados sem a concepção ou a crença de um ser sensível e pensante, se o fundamento de nosso ser é uma força ou uma causa de movimento, é verdadeiro dizer que o fundamento de nosso ser é dado por nós independentemente de toda modificação acidental, e o exercício da imaginação e do raciocínio ou o conhecimento destas faculdades não podem nos assegurar da realidade de nossa alma substância, mas esta realidade é sentida ou apercebida imediatamente apenas pelo sentido íntimo. (BIRAN, 1942, p. 226).
\end{abstract}

Noutra passagem de Kinker (1801) transcrita por Biran (1942), constata-se "a ipseidade do sujeito, cuja a consciência acompanha-me em todas as percepções, não observando a percepção de minha alma como objeto, ou seja, tal qual é em si mesma e independentemente do sentido íntimo". Quanto a isso, Maine de Biran dirá que:

\begin{abstract}
Se o sentido íntimo da ipseidade constitui a essência da alma, é impossível despoja-la sem aniquila-la, como se a resistência constituísse a essência da matéria, não podemos realizar abstração sem excluir sua matéria. Nós não sabemos, é verdade se a alma desprovida deste sentido íntimo não seria um objeto real para o ser supremo, mas ao menos é verdade que nossa ignorância sobre o que seria a alma destituída do porque ela é alma ou ser atuante e pensante, não nos impediria de conceber sua realidade vigente, sob tal atributo essencial. (BIRAN, 1942, p. 226).
\end{abstract}

Embasado por essa concepção, Maine de Biran (BIRAN, 1942, p. 226) protesta que "o vício de Kant consiste em concluir de nossa ignorância intransponível sobre o que é uma coisaem-si, nossa ignorância da realidade absoluta desta coisa, pois a concebemos com o auxílio de nossas faculdades". Sim, destaca Biran (BIRAN, 1942, p. 226), é possível que alguma coisa seja diferente da forma que a concebemos, que tenha vários atributos que nos são desconhecidos ou, ainda, que seja como a conhecemos e não contenha mais do que um único atributo sobre o qual se manifesta o nosso espírito. Contudo essas questões estão além do julgo do homem. Não julgamos

OLIVEIRA, André Renato de. Dissonâncias e ressonâncias da filosofia kantiana sobre a filosofia de Maine de Biran. Griot : Revista de Filosofia, Amargosa - BA, v.21 n.3, p.408-425, outubro, 2021. 
essas questões, pois as conhecemos apenas pelas faculdades, mas ao menos reconhecemos que a coisa que concebemos sob o atributo essencial a nossa natureza existe enquanto atributo. Observemos, nesta passagem de Kinker (1801) discutida por Biran (1942), uma contribuição à questão; analisemos primeiramente a passagem e depois a recensão. "Esta consciência de minha própria existência, se conservaria se me representasse outros seres, como existentes fora de mim; enquanto que sem eles eu não poderia adquirir percepções?".

A isso, Maine de Biran (BIRAN, 1942, p. 227) responde da seguinte forma, minha alma poderia ser reduzida ao sentimento de suas forças ou de sua ação constante sobre o corpo inerte, sem nenhuma percepção acidental. É o que ocorre no sono; nossa força reduzida à inércia absoluta e sem termo de aplicação. Assim, a união substancial de uma alma com um corpo pode ser durável e se estender a outro modo de existência. Maine de Biran (BIRAN, 1942, p. 227) é categórico ao sustentar que "o sentido íntimo de nossa individualidade não é um atributo ou predicado da alma, é a alma sentindo ou legitimando a si mesma na ação que lhe é essencial, e ela não poderia ser destituída deste sentido íntimo...". O filósofo francês segue: "Não há necessidade de realizar uma distinção entre este pretenso atributo e o sujeito; pois há apenas modos acidentais do pensamento que podem ser considerados como predicados do sujeito pensante, sem que o sujeito que se encontre totalmente no sentido íntimo e, por conseguinte, este mesmo sentido íntimo possa ser considerado como predicado".

Toda a problemática gravita em torno da questão: “O que é, independentemente de suas percepções e de seus pensamentos, este eu que sente, que pensa e que tem a consciência de seu sentir e de seu pensar?" (KINKER, 1801, p. 104). Para Biran (BIRAN,1942, p. 227), é esse o nó górdio da psicologia ou metafísica da alma. Maine de Biran (BIRAN, 1942, pp. 227-228) sustenta que a resposta a essa questão está no sentido íntimo, pois “o eu que tem consciência de tudo o que sente e pensa é independente, tanto do sentido íntimo de sua individualidade quanto de toda sensação ou pensamento acidental sobre ele". Seria essa concepção de sentido íntimo a resolução ao nó que deteve os metafísicos, como Biran descreveu, além de ser o conceito fundamental de seu sistema e aquele que poderia preencher o abismo kantiano. 


\section{Referências}

AMPÈre, A, M. Philosophie Des Deux Ampere $2^{\circ}$ edição, Paris: Didier e cia, 1870.

COUSIN, V. Oeuvres philosophiques de Maine de Biran, Paris: Librairie de Lagrand, 1841.

GOUHIER, H. Maine de Biran oeuvres choisies, Paris: Aubier, 1942.

KANT, I. Kant's Gesammelte Schriften Akademieausgabe", Königlich Preu Bische Akademie der Wissenschaften, Berlin 1900ff. (bisher 29 Bände), Reimer, ab 1922 de Gruyter.

KINKER, J. Essai d'une exposition succincte de la Critique de la raison-pure, Amsterdam: Changuion, 1801.

NAVILLE, E. Oeuvres Inédites De Maine De Biran 3 vol, Paris: Dezobry, E. Magdeleine et cia, 1859.

TISSERAND, P. Oeuvres de Maine de Biran: Correspondance philosophique, Paris: Félix Alcan, 1920.

VALLOIS, M. La formation de l'influence kantienne em France, Paris: Félix Alcan, 1920.

VILLERS, C. Philosophie de Kant ou Principes Fondamentaux de La Philosophie Transcendentale, Pari: Collignon e Metz, 1801.

Autor(a) para correspondência / Corresponding author: André Renato de Oliveira. andrerpro@hotmail.com 